\title{
THEORIES, CONCEPTS AND THE RUGBY WORLD CUP: USING MANAGEMENT TO UNDERSTAND SPORT
}

\section{Andy Adcroft and Jon Teckman}

Type of Paper: Research paper

\section{Purpose of this paper}

The aim of this paper is consider the versatility of management theory by testing it in a non-management context, in this case sport in general and the Rugby World Cup in particular.

\section{Design}

The paper develops a theoretical discussion of performance and competitiveness into a conceptual model before using that model to analyse and discuss the causes of success and failure in the Rugby World Cup.

\section{Findings}

Understanding the outcome of sporting contests is a complex activity. In the examples discussed, success or failure is the product of both the internal characteristics of the contestants and the external conditions of the contest itself. The findings of the research are robust in their reliability and validity.

\section{Originality/Value}

Originality lies in a number of areas. Theory is used to develop an original conceptual model and it is then tested in an original context. The value of the paper lies as much in the investigations it opens up as in the debates it closes.

\section{Key Words}

Contests

Sport

Performance orientation

Competitive orientation

Rugby World Cup

Outcomes 


\section{THEORIES, CONCEPTS AND THE RUGBY WORLD CUP: USING MANAGEMENT TO UNDERSTAND SPORT}

\section{Introduction}

Hegel argued that everyone is a child of their times; what we are, the things we do, the beliefs and values we hold are the product of ourselves as individuals and the world in which we live. Hegel's analysis of the individual as having internal and external determinants can be broadly applied at the level of organisations and much social scientific discourse is careful to place any organisational analysis into a broader environmental context where the conditions in one are reflected in the behaviour found in the other. In economics, for example, firm behaviour is explained by the competitive conditions faced in the marketplace and sociology examines the fundamental relationship between the individual and the society in which he or she lives. This internal-external relationship is also central in much management theory in subject areas like organisational behaviour and corporate strategy. For example, whilst Chaharbaghi and Willis (1996) found over fifty widely used definitions of corporate strategy, what was central to most of them was the relationship between the organisation and the world in which it operates. The aim of this paper is to examine this dynamic in the context of sport and, in doing so, the paper offers a novel and innovative approach to understanding the determinants of contested outcomes in sport.

In using sport as the context for theoretical discussion, this paper accepts Liu et al's (1998) point that "there is an extensive literature available which shows us that there is considerable synergy and correlation between sports and business" (p.93). Furthermore, Espitia-Escuer and Garcia-Cebrian (2006) suggest two general reasons why sport has and can be used as a context for management research. First is the widespread interest in sport both within and outside academic circles and, second, is the ready availability of statistical data which allows for serious empirical research. In explaining these drivers, Espitia-Escuer and Garcia-Cebrian identify 13 major studies over the past two and a half decades which have used sporting data to make more general management points. In these studies the central aim has been to make general points about management theory through the use of sporting examples but this paper takes an opposite track; our aim is not so much to advance knowledge of management theory but rather to demonstrate that management theory can be used to advance knowledge of non-traditional contexts for management research, in this case sport in general and Rugby World Cup (RWC) in particular.

Our argument, therefore, is that management theory is versatile and allows for serious investigation of wider phenomena. This is for four reasons. First, there are many issues common to both the study of sport and the study of management. For example, success in both areas can be influenced by the 
judicious use of strategy, motivation, team working and leadership. Second, sport is very much concerned with the traditional management task of allocating scarce and finite resources in order to muster the best possible outcomes; Football teams can only have 11 players, sprint races last for just 100 metres and so on. Third, sport offers clear, tangible and measurable outcomes; even in complicated games like cricket, for example, there are only four possible results and each of these results is clear to all observers. Finally, sport, like business strategy, is about contests whether it is the one on one contest of a knock-out tournament or the multi-faceted and long term contest of a league.

The paper is organised in a fairly straightforward way. The next section establishes the theoretical basis for the investigation through an examination of the related concepts of performance orientation and competitive orientation. The section develops the theory into a conceptual model which examines the dynamic relationship between (internal) performance and (external) competitiveness. The next section explains the approach taken to the operationalisation of the model and how evidence is developed, analysed and utilised. Following on from this explanation of methodology, we present the evidence on performance and competitive orientation from the 6 RWCs held between 1987 and 2007 before a concluding section considers the implications of the research for both the theory of management and the practice of sport.

\section{Literature Review}

The initial elements of theory which underpin this paper are the closely related issues of performance management and performance measurement. One of the main advantages of having this as the point of theoretical departure is that " $a$ substantial body of literature on performance management has developed since the 1970s" (Boland and Fowler, 2000, p.417) and this body of work has meant that "there has been a revolution in performance measurement and performance management over the past 20 years with the enormous interest reflecting itself in practitioner and academic conferences and papers" (Radnor and McGuire, 2004, p.246). However, as with many things social scientific, volume does not necessarily equate to consensus. For example, in discussing high performance management, Lloyd and Payne (2004) suggest that it has "no clear definition" and that there is a "fundamental lack of agreement about the specific practices" (p.14). The result, therefore, of decades of academic research is a name without an agreed meaning and a significant volume of literature which remains "impoverished conceptually" (Butler et al. 2004, p.4).

Whilst the link between process and outcome is frequently stated (and often assumed), it is not always absolutely clear. On the one hand there is Ness and Cucuzza's (1995) argument that "when it happens you can bet the company's performance will show it" (p. 70) and this clear causality is much supported in 
the literature. A review of the relevant literature by Ashton and Sung (2002) came to the conclusions that "scientific research has now established a strong link ... and the skills associated with them pays off on the bottom line". We would offer a number of caveats to this position. First, as Butler et al. (2004) suggest, the direction of causality has not been fundamentally determined. Are organisations successful because they have the best processes or does success provide organisations with the time and resources to develop the best processes? Second, the direct impact of specific process interventions can be hard to identify and, hence, measure. For example, Appelbaum et al. (2000) point out that different studies (of similar phenomena) make different claims as to the impacts of management interventions. Finally, Williams et al. (1993) argue that there is a major problem of complexity because outcomes are determined as much by external conditions such as market conditions, industry structures and social settlements as they are by purposive management action.

The second problem is that conclusions can be difficult to draw because it always depends on what and how things are measured. One of the most influential works on organisational design by Huber et al. (1979) suggests that the first step towards success is the identification and measurement of the "relevant" variables. Only once this is done can interventions be designed, applied and, ultimately, assessed for efficacy. One problem with this is the extent to which such a deconstructive approach accurately reflects the reality of organisational processes. Adcroft and Willis (2005) suggest that the more individual variables are identified and measured the less the whole service or organisation is being assessed especially when those measures can be chosen to cynically influence the perceived outcome. In dealing with this issue, Williams et al. (1993) suggest that any sensible choice of measures must always include a combination of internal (organisational) and external (environmental) variables which has the benefit of providing more accuracy but the drawback of making understanding necessarily more complex and difficult. Keep (2000) suggests that this can be resolved if performance is examined in terms of both "demand and supply side interventions" (p.8) and this is supported by Kaplan and Norton's (1992) point that "managers be able to view performance in several areas simultaneously" (p.72). A reasonable summing up of the issue comes from Modell (2004) who asks "how does the interplay between different collectives of actors within organisations and the institutional macro environment ... influence organisational actions?" (p.51) before concluding that "more in-depth examination" is needed.

In dealing with Modell's point, the theoretical/conceptual basis of this paper rests on the argument that any outcome enjoyed by an organisation is the product of two key factors; the ability of that organisation to perform and the ability of that organisation to compete. The different blends of performing and competing across organisations in, for example, the same industry or market, provides valuable insights into the varying degrees of success and failure and the root 
causes thereof both in the short and longer term. How an organisation performs is essentially concerned with what happens within the boundaries of that organisation, its collection of activities and systems and the way in which they are managed. It is also about a mindset, Performance Orientation, which draws on literature from a diverse range of disciplines and subjects such as psychology, performance management and organisational behaviour. How an organisation competes, on the other hand, is more externally driven and is primarily concerned with how the organisation interacts with others in its chosen marketplace. Again this mindset of competition, Competitive Orientation, draws on a variety of disciplines like marketing, strategy and, again, psychology.

We begin with performance orientation. Simons et al. (2000) suggest that individuals with a high performance orientation are "preoccupied with themse/ves and the way others perceive them" (p.336); there is a clear internal focus in terms of both what is done and how those activities should be recognised. This is supported by Coad and Berry (1998) who point out that the recognition will be driven by peers within the organisation and further elaborated on by Coad (1999) who points out the importance of "important others" for recognition within the organisation such as those on whom advancement may depend. Huddleston and Garvin (1995) point out that in sport what matters is, for example, individual runs, goals or points scored much more than the team's result. This point is supported by Porter (2005) who notes that in organisations with a strong performance orientation, efforts are usually directed at individuals rather than teams or groups.

If the first key characteristic of performance orientation is, therefore, the focus internally, then the second key characteristic is the activities and beliefs that such an orientation would foster. Porter's research suggests a view amongst those with a performance orientation that there is little value in working on something that you are not very good at. Simons et al. argue that this orientation is about establishing where competence lies as that is the fundamental determinant of outcomes. These competencies, according to Stiles et al. (1997) will tend to be managed through clear and strict measures where the focus is on optimisation through seemingly endless repetition, practice and rehearsal. Unsurprisingly, this orientation often leads to the avoidance of challenge, struggle, experiment and innovation (Coad and Berry) and tends to work best in environments where there is "a lack of novelty, complexity and open-endedness" (Coad, p.114).

In discussing the difference between a performance and a competitive orientation, Lyle (1997) suggests that they are part of a continuum and that it is likely that organisations and individuals will pass from one to the other. Thus, performance orientation is about the development of potential for excellence and competitive orientation is about translating that potential into practice in a 
contested environment. At its most extreme, "hypercompetitiveness", Ryckman et al. (1997) suggest that it is "a need by individuals to compete and win (and avoid losing) at any cost" (p.271). More moderately, Covin and Covin (1990) suggest that competitive orientation is a "general management disposition reflected in a firm's willingness to take on and desire to dominate competitors through a combination of proactive moves and innovative efforts" (p.36). Thus the first key factor which differentiates competitive from performance orientation is its focus; competitive orientation focuses externally on the market place and more explicitly on outcomes rather than processes.

A different focus of attention would, naturally, lead to a different set of activities and behaviours. Perry and Shao (2005) identify four key activities and behaviours which underpin a competitive orientation. There will be clear attention paid to the acquisition and dissemination of competitor information, more time will be spent attempting to predict competitor actions, more time will be spent attempting to influence competitors and resources will be allocated to the identification and exploitation of competitor weaknesses. These activities are summed up by Gatignon and Xuereb (1997) who suggest that whilst performance orientation is simply about improvements to performance, competitive orientation is about improvements to relative performance in order to secure a competitive advantage. These issues are developed further by Lyle who argues that a competitive orientation is about "the highest levels of achievement in competition" (p.314) where the focus is much more likely to be on innovation, challenge and risk-taking (Gatignon and Xuereb).

In translating these performance and competitive orientation characteristics into a sports context we would suggest the following as summarized in Table 1: 


\section{Table 1: Key characteristics of performance and competitive orientation in a sporting context}

\begin{tabular}{|c|c|}
\hline PERFORMANCE ORIENTATION & COMPETITIVE ORIENTATION \\
\hline $\begin{array}{l}\text { Mindset } \\
\text { - Internal and self centred } \\
\text { - Process driven, how things are } \\
\text { done is important } \\
\text { - The aesthetics of performance } \\
\text { really matter }\end{array}$ & $\begin{array}{l}\text { Mindset } \\
\text { - External and relative } \\
\text { - Outcomes and what is } \\
\text { achieved } \\
\text { - Aesthetics are an optional } \\
\text { extra and can be easily } \\
\text { discarded }\end{array}$ \\
\hline $\begin{array}{l}\text { Objectives } \\
\text { - Process based } \\
\text { - Arrived at through a } \\
\text { deconstructive process } \\
\text { - Aimed at self, rarely externally } \\
\text { compared } \\
\text { - Sliding scale of achievement }\end{array}$ & $\begin{array}{l}\text { Objectives } \\
\text { - Outcome/Result driven } \\
\text { - Determined in the contested } \\
\text { arena } \\
\text { - Targets are set as absolute } \\
\text { attributes } \\
\text { - Clear emphasis on current, not } \\
\text { future, contests }\end{array}$ \\
\hline $\begin{array}{l}\text { Focus } \\
\text { - Reliability within a set of } \\
\text { parameters } \\
\text { - Focus on improvements over } \\
\text { time and fulfilling potential } \\
\text { - Physical and tangible measures } \\
\text { of performance }\end{array}$ & $\begin{array}{l}\text { Focus } \\
\text { - Reliability under pressure } \\
\text { - Winning when it counts } \\
\text { - Outcome/Results driven } \\
\text { - Mental elements of process } \\
\text { really matter }\end{array}$ \\
\hline $\begin{array}{l}\text { Style } \\
\text { - Rigid, inflexible, prescriptive } \\
\text { - Pre-set patterns are important } \\
\text { - Rehearsal and practice }\end{array}$ & $\begin{aligned} & \text { Style } \\
& \text { - Adaptive to circumstances } \\
& \text { - Improvisation/Innovation/ } \\
& \text { Emergent } \\
& \text { - Empowering experienced team } \\
& \text { members }\end{aligned}$ \\
\hline
\end{tabular}

Conceptually and diagrammatically the blend of performance and competitive orientation creates four possible positions for the players within any given contest. The first position is the Ideal Position where the player demonstrates a high level of both performance and competitivity. From this position a player will dominate the contest, possibly over a long period of time, and the emphasis will be on activities and improvements which maintain and enhance the dominant position. Players are most likely to find themselves in this position as a result of long periods of stability, for example in a world class team where changes in constituents have been made in a gradual manner. At the opposite end of this position is the Worst Position where players have neither the performance level nor the competitive instincts to win out in a contest. In this position, defeat is 
the most common occurrence and the emphasis may be on building up a young team for the future or refreshing a team whose results are in decline. In this position, any kind of competitive advantage, no matter how small or fleeting, is strived for. The third position, Competitors, is those players who will be able to pull off the occasional upset through exploitation of competitive characteristics to overcome performance inferiority. The emphasis of activity is likely to be on introducing consistency to performance and the exploitation and development of potential. The final position, Performers, is for those players who may occasionally dominate a contest but are susceptible to defeat when faced with pressure situations. Development of these players may emphasize mental strength. Figure 1 shows these.

\section{Figure 1: Performance and Competitive Orientation Matrix}

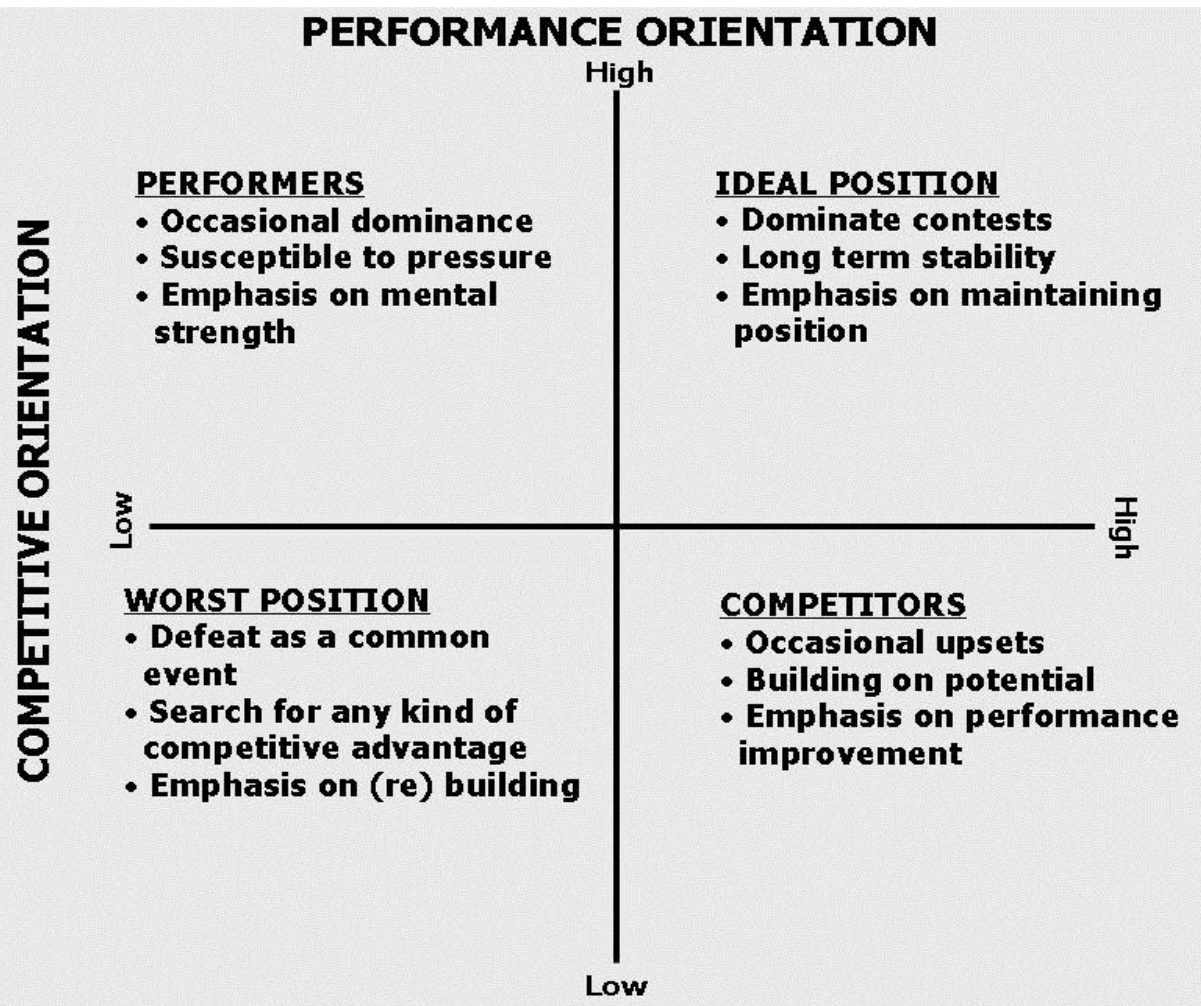

Having established the theoretical and contextual foundations of this paper, we now turn to explain the methodology through which we examine this conceptual model and the underpinning theory. 


\section{Methodology}

The RWC provides an ideal context in which to apply and test the model developed in the previous section. The tournament has been played six times over the past 20 years and the format has remained reasonably constant with a group or league stage followed by three knock-out rounds until the ultimate winner is found. This consistency of format is also reflected in consistency amongst the participants where the same teams have competed at the top end of the RWC in each year it has been held. The RWC, therefore, provides a reasonably consistent sample in which it is possible to track changes (and lack of changes) in how each team enters into contested situations. The game itself is also a useful vehicle because of its nature; unlike sports like football which thrive on their simplicity, rugby union is a complicated game and this is reflected in, for example, its scoring system. Whilst there is just one way to score in football, in rugby union there are four different ways in which points can be scored and tracking the patterns of how individual teams score these points can be a useful way to measure performance and competitive orientation.

Theoretically driven research is, necessarily, grounded in assumptions. The approach we take to analysing the 233 matches in the six RWCs under consideration is built on a set of assumptions which begin with the notion that the outcome of any sporting contest is based on two things; First, how each team in that contest performs and, second, how each team in that contest competes. Contestants can be differentiated by their blend of performance and competitive characteristics. For example, performance can be a product of such things as physical ability, preparation and the quality of training whereas competitiveness can be a product of mental toughness and a willingness to change strategy and tactics. Over time, therefore, it is likely that, as teams develop, their blend of performance and competitiveness will change and this is crucial as different forms of contest will require different attributes; success in a league or group situation will require a different set of strengths compared to success in a knock-out situation. Whilst there will always be teams which excel at both performance and competition, it is likely that these teams will be the exception rather than rule; most teams will try and use strengths in one area to overcome weaknesses in the other. In this context, our final assumption is that the team which wins out in a contested situation is the team which has the most favourable blend of performance and competitive orientations.

In measuring performance and competitiveness across all the teams who have played in the RWC over the past 20 years, there are two central problems to overcome. First, as all the teams in the tournament do not play each other, it can be difficult to assess relative performance and competitiveness between teams who have never met on the field of play. For example, in 2007, the winning team, South Africa, played just seven matches against six opponents in 
a tournament in which 20 teams took part. The second problem is that some teams are not only better, but are significantly better, than other teams which creates issues of comparability; how do you compare the performance and competitiveness of a team which scores, for example, over 100 points against the worst team in the tournament with a mid ranking team which loses narrowly to one of the better teams? The inevitable outcome of these issues is that measuring competitiveness is likely to be much more complicated and controversial than measuring performance. It is the latter, however, with which we begin.

As rugby union is very much a game driven by statistics and numbers, generating measures of performance is relatively simple. All the raw data for this paper is taken from the official site of the RWC (www.rugbyworldcup.com). For our purposes we have chosen 10 measures of performance which range across four broad categories; the results of matches played, performance in attack, performance in defence and the manner of victory or defeat. The measures in the first category are a simple measure of the proportion of matches won out of those matches played by each team and, in order to reward those teams who progress further in the tournament, the number of matches won. We also measure the scale of victory (or defeat) by measuring the points difference between teams in each match. Attacking performance is measured in two ways; the average number of points scored and the average number of tries scored in each game played. Similarly, defensive performance is measured by average points and tries conceded in each match played. Finally we measure the manner of victory or defeat by looking at the proportion of points scored from tries (and conversions), the strength of each opponent played and the average difference between tries scored and conceded in each game. Each of these measures is indexed with the best performing team indexed at 100 . The indices for each measure are then totalled before the sum is then re-indexed in order to generate an overall performance orientation index. An example of this for the quarter finalists in the 1995 RWC is shown in the table below. 
Table 2: $\quad$ Performance Indexes for the quarter finalists in the 1995 RWC.

\begin{tabular}{|c|c|c|c|c|c|c|c|c|}
\hline & Australia & England & France & Ireland & $\begin{array}{c}\text { New } \\
\text { Zealand }\end{array}$ & Samoa & Scotland & $\begin{array}{l}\text { South } \\
\text { Africa }\end{array}$ \\
\hline $\begin{array}{l}\text { Proportion } \\
\text { of matches } \\
\text { won }\end{array}$ & 50 & 67 & 83 & 50 & 83 & 50 & 50 & 100 \\
\hline $\begin{array}{l}\text { Number of } \\
\text { matches } \\
\text { won }\end{array}$ & 33 & 67 & 83 & 33 & 83 & 33 & 33 & 100 \\
\hline $\begin{array}{l}\text { Points } \\
\text { difference } \\
\text { per game }\end{array}$ & 76 & 67 & 82 & 59 & 100 & 60 & 91 & 78 \\
\hline $\begin{array}{l}\text { Points } \\
\text { scored per } \\
\text { game }\end{array}$ & 50 & 48 & 56 & 48 & 100 & 50 & 82 & 44 \\
\hline $\begin{array}{l}\text { Tries scored } \\
\text { per game }\end{array}$ & 44 & 27 & 41 & 48 & 100 & 51 & 73 & 32 \\
\hline $\begin{array}{l}\text { Points } \\
\text { conceded } \\
\text { per game }\end{array}$ & 68 & 46 & 77 & 34 & 56 & 34 & 60 & 100 \\
\hline $\begin{array}{l}\text { Tries } \\
\text { conceded } \\
\text { per game }\end{array}$ & 83 & 31 & 100 & 26 & 42 & 24 & 42 & 100 \\
\hline $\begin{array}{l}\text { Proportion } \\
\text { of points } \\
\text { from tries }\end{array}$ & 79 & 47 & 59 & 87 & 87 & 82 & 76 & 59 \\
\hline $\begin{array}{l}\text { Strength of } \\
\text { opposition }\end{array}$ & 65 & 89 & 73 & 85 & 77 & 75 & 79 & 83 \\
\hline $\begin{array}{l}\text { Tries } \\
\text { difference } \\
\text { per game }\end{array}$ & 80 & 59 & 80 & 65 & 100 & 65 & 87 & 75 \\
\hline Total & 627 & 548 & 735 & 535 & 829 & 525 & 673 & 771 \\
\hline $\begin{array}{l}\text { Performance } \\
\text { Orientation } \\
\text { Index }\end{array}$ & 76 & 66 & 89 & 65 & 100 & 63 & 81 & 93 \\
\hline
\end{tabular}

(Source: www.rugbyworldcup.com)

Having explained the measurement of performance for each team we now turn to the measurement of competitiveness. Given that some of the characteristics of competitive orientation which mark it out as different to a performance orientation are the focus on measures which are absolute, relative and external, it is in this area that we deal with the problems of comparability mentioned earlier. We begin with a discussion of what we would expect to see from a team with a high competitive orientation. On the basis of the theory and concept discussed previously, we would suggest that a competitive team would have a number of characteristics such as an ability to win matches despite poor performances, an ability to win matches in an unaesthetic or ugly manner, an 
ability to win matches against better opposition and an ability to win high pressure matches in, for example, the knock-out stages of the tournament. In measuring these characteristics a weighting system was developed based on the performance index above with the best performing team in each RWC weighted at 1 and all other teams compared to this. In the example in Table 2, therefore, in the 1995 RWC New Zealand were weighted at 1, South Africa at 0.93, France at 0.89 , Scotland at 0.81 down to Samoa weighted at 0.63 .

In measuring competitiveness, five different measures were generated and this weighting system was then used in four of them. All results in all games were recalculated on the basis of the weightings. For example, when New Zealand played Japan in the 1995 RWC the result was a victory by 145 points to 17 . Using the weighting system, each point New Zealand scored was rated at 0.35 (Japan's weighting) and each point Japan scored was rated at 1 (New Zealand's weighting) giving a weighted victory to New Zealand by 50.75 points to 17 . Table 3 shows how the weighting system worked for the all the games played by the tournament winners, South Africa (weighted at 0,93). Under this weighting system, South Africa would have narrowly lost one of their games.

\section{Table 3: Actual and weighted results for South Africa in the 1995 RWC}

\begin{tabular}{|l|l|l|l|l|l|l|}
\hline Opponent & Australia & Romania & Canada & Samoa & France & $\begin{array}{l}\text { New } \\
\text { Zealand }\end{array}$ \\
\hline Weighting & 0.76 & 0.32 & 0.56 & 0.63 & 0.89 & 1.00 \\
\hline $\begin{array}{l}\text { Actual } \\
\text { points } \\
\text { scored }\end{array}$ & 27 & 21 & 20 & 42 & 19 & 15 \\
\hline $\begin{array}{l}\text { Weighted } \\
\text { points } \\
\text { scored }\end{array}$ & 20.52 & 6.72 & 11.20 & 26.46 & 16.91 & 15.00 \\
\hline $\begin{array}{l}\text { Actual } \\
\text { points } \\
\text { conceded }\end{array}$ & 18 & 8 & 0 & 14 & 15 & 12 \\
\hline $\begin{array}{l}\text { Weighted } \\
\text { points } \\
\text { conceded }\end{array}$ & 16.74 & 7.44 & 0 & 13.02 & 19.95 & 11.16 \\
\hline $\begin{array}{l}\text { Actual } \\
\text { result }\end{array}$ & Won by 9 & Won by 13 & Won by 20 & Won by 28 & Won by 4 & Won by 3 \\
\hline $\begin{array}{l}\text { Weighed } \\
\text { result }\end{array}$ & $\begin{array}{l}\text { Won by } \\
3.78\end{array}$ & $\begin{array}{l}\text { Lost by } \\
0.72\end{array}$ & $\begin{array}{l}\text { Won by } \\
11.20\end{array}$ & $\begin{array}{l}\text { Won by } \\
13.44\end{array}$ & $\begin{array}{l}\text { Won by } \\
2.96\end{array}$ & $\begin{array}{l}\text { Won } \\
\text { (Source: }\end{array}$
\end{tabular}

(Source: www.rugbyworldcup.com)

On the basis of this calculation, two measures of competitiveness were generated; the proportion of weighted matches won and the number of weighted matches won. The weighting system was also used in assessing the quality of opposition through the average weighting of opponents in the group stages of 
the tournament and the average weighting of opponents in matches won. The final measure of competitiveness was the proportion of total points scored by each team from penalties and drop goals as a proxy for the team's ability to win matches without scoring tries. Each measure was indexed with the leading team indexed at 100, the indices were added together and a final competitive orientation index was created in the same way as in calculating the performance orientation index. An example of this is shown in the table below for the same teams shown earlier in the 1995 RWC.

Table 4: Competitiveness Indexes for the quarter finalists in the

\section{RWC.}

\begin{tabular}{|c|c|c|c|c|c|c|c|c|}
\hline & Australia & England & France & Ireland & $\begin{array}{c}\text { New } \\
\text { Zealand }\end{array}$ & Samoa & Scotland & $\begin{array}{l}\text { South } \\
\text { Africa }\end{array}$ \\
\hline $\begin{array}{l}\text { Proportion of } \\
\text { weighted } \\
\text { matches won }\end{array}$ & 60 & 80 & 80 & 30 & 100 & 60 & 60 & 100 \\
\hline $\begin{array}{l}\text { Number of } \\
\text { weighted } \\
\text { matches won }\end{array}$ & 40 & 80 & 80 & 20 & 100 & 40 & 40 & 100 \\
\hline $\begin{array}{l}\text { Average } \\
\text { weighting of } \\
\text { group } \\
\text { opponents }\end{array}$ & 79 & 74 & 72 & 87 & 71 & 75 & 76 & 72 \\
\hline $\begin{array}{l}\text { Average } \\
\text { weighting of } \\
\text { opponents } \\
\text { beaten }\end{array}$ & 47 & 66 & 72 & 68 & 67 & 57 & 45 & 83 \\
\hline $\begin{array}{l}\text { Proportion of } \\
\text { points from } \\
\text { penalties and } \\
\text { drop goals }\end{array}$ & 39 & 86 & 69 & 27 & 27 & 34 & 44 & 69 \\
\hline Total & 266 & 385 & 373 & 231 & 365 & 266 & 265 & 423 \\
\hline $\begin{array}{l}\text { Competitive } \\
\text { Orientation } \\
\text { Index }\end{array}$ & 63 & 91 & 88 & 55 & 86 & 63 & 63 & 100 \\
\hline
\end{tabular}

(Source: www.rugbyworldcup.com)

The key test of these measures is the extent to which they are valid and reliable; do they measure what they are supposed to measure and do they get the right result on a consistent basis? One of the advantages of using the RWC as an example is that all the results are known and so it is possible to compare the results of our analysis with what actually happened during the tournaments. In order to do this, two further elements were added to the analysis. First, the indices for performance and competitive orientation were plotted on a matrix based on the conceptual model developed in the previous section in order to allow for some kind of comparison of the way in which different teams compete 
across the whole tournament. An example from the 1995 RWC is shown in Figure 2 below.

\section{Figure 2: Performance-Competitiveness matrix for the 1995 RWC}

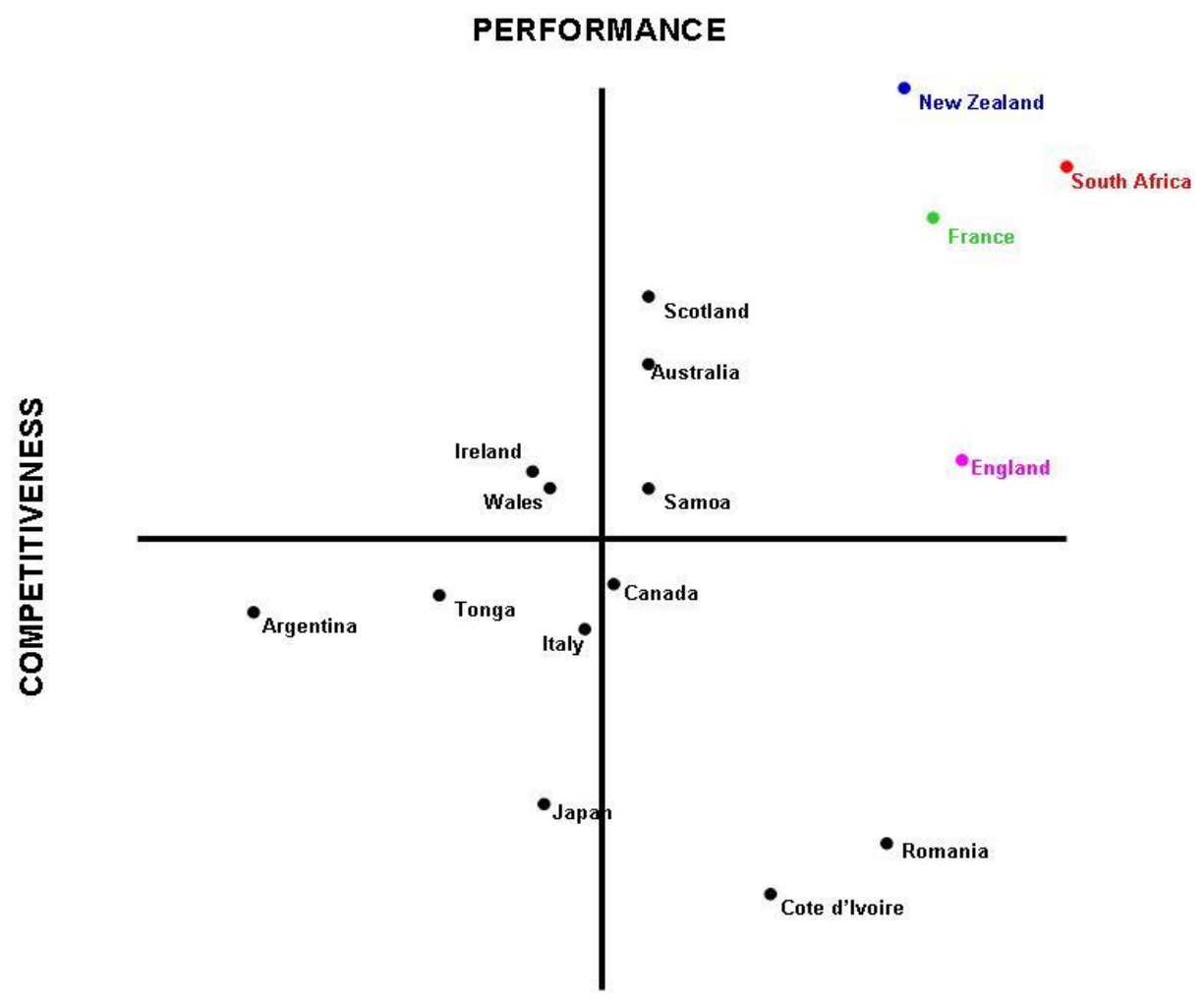

(Source: www.rugbyworldcup.com)

Having established the relative positions of all teams in the RWC on the basis of performance and competitiveness, we then analysed the positions of each team on the basis of the combination of performance and competitiveness. This we did by the simple mathematical expedient of multiplying one by the other, the product of the two orientations we refer to as the team's PC Score. Table 5 below gives a summary of performance orientation, competitive orientation and PC Score for the 8 teams used so far in the 1995 RWC 
Table 5: Performance Orientation, Competitive Orientation and PC Score for the quarter finalists in the 1995 RWC

\begin{tabular}{|l|c|c|c|c|c|c|c|c|}
\hline & Australia & England & France & Ireland & $\begin{array}{c}\text { New } \\
\text { Zealand }\end{array}$ & Samoa & Scotland & $\begin{array}{c}\text { South } \\
\text { Africa }\end{array}$ \\
\hline $\begin{array}{l}\text { Performance } \\
\text { Orientation }\end{array}$ & 76 & 66 & 89 & 65 & 100 & 63 & 81 & 93 \\
\hline $\begin{array}{l}\text { Competitive } \\
\text { Orientation }\end{array}$ & 63 & 91 & 88 & 55 & 86 & 63 & 63 & 100 \\
\hline PC Score & $\mathbf{4 7 8 8}$ & $\mathbf{6 0 0 6}$ & $\mathbf{7 8 3 2}$ & $\mathbf{3 5 7 5}$ & $\mathbf{8 6 0 0}$ & $\mathbf{3 9 6 9}$ & $\mathbf{5 1 0 3}$ & $\mathbf{9 3 0 0}$ \\
\hline
\end{tabular}

(Source: www.rugbyworldcup.com)

The validity and reliability of this approach is first tested on a match by match basis. If the PC Score generated for each team is an accurate reflection of that team's ability then, ceteris paribus, the team with the higher PC Score should beat the team with the lower PC Score whenever they played against each other. The second element to the testing of reliability and validity was the extent to which this approach identified two things. First, did it correctly identify the team that won the tournament overall; did the team with the highest PC Score win the RWC? Second, did the approach identify the relative positions in which each team finished in the RWC? Across all of these measures and assessments, the approach has proven to be both reliable and valid. Over the 20 years of the RWC, 233 matches have been played and our approach identifies the winner in 215 of those matches. This represents a success rate of $92 \%$. The matches in which it failed to identify the winner were either matches that ended up as a draw or matches with a significant upset. In terms of the tournament as a whole, the approach correctly identifies 21 out of the total of 24 semi-finalists across all six RWCs and, in every single case, correctly identifies the winner of the tournament. We now turn to present the results of our analysis across the six RWCs played between 1987 and 2007.

\section{Findings}

In presenting our findings we will begin with some general points about the nature of competition in the RWC before moving onto a more specific discussion of how teams enter into contests. Over the twenty years that the RWC has been held, there have been two winners who have absolutely dominated the tournament from start to finish. In 1987 New Zealand won with performance levels almost one quarter higher than their nearest rivals and competitiveness higher by almost 15\%. In 1999, Australia won the RWC, again by dominating the tournament albeit not at the same level as New Zealand eight years previously. As an example, Figure 3 below shows each team in the 1999 RWC plotted onto the performance-competitiveness matrix developed earlier and clearly shows Australia as the outstanding team with a number of other teams competing at or about the same levels of performance and competitiveness. 


\section{Figure 3: Performance-Competitiveness matrix for the 1999 RWC}

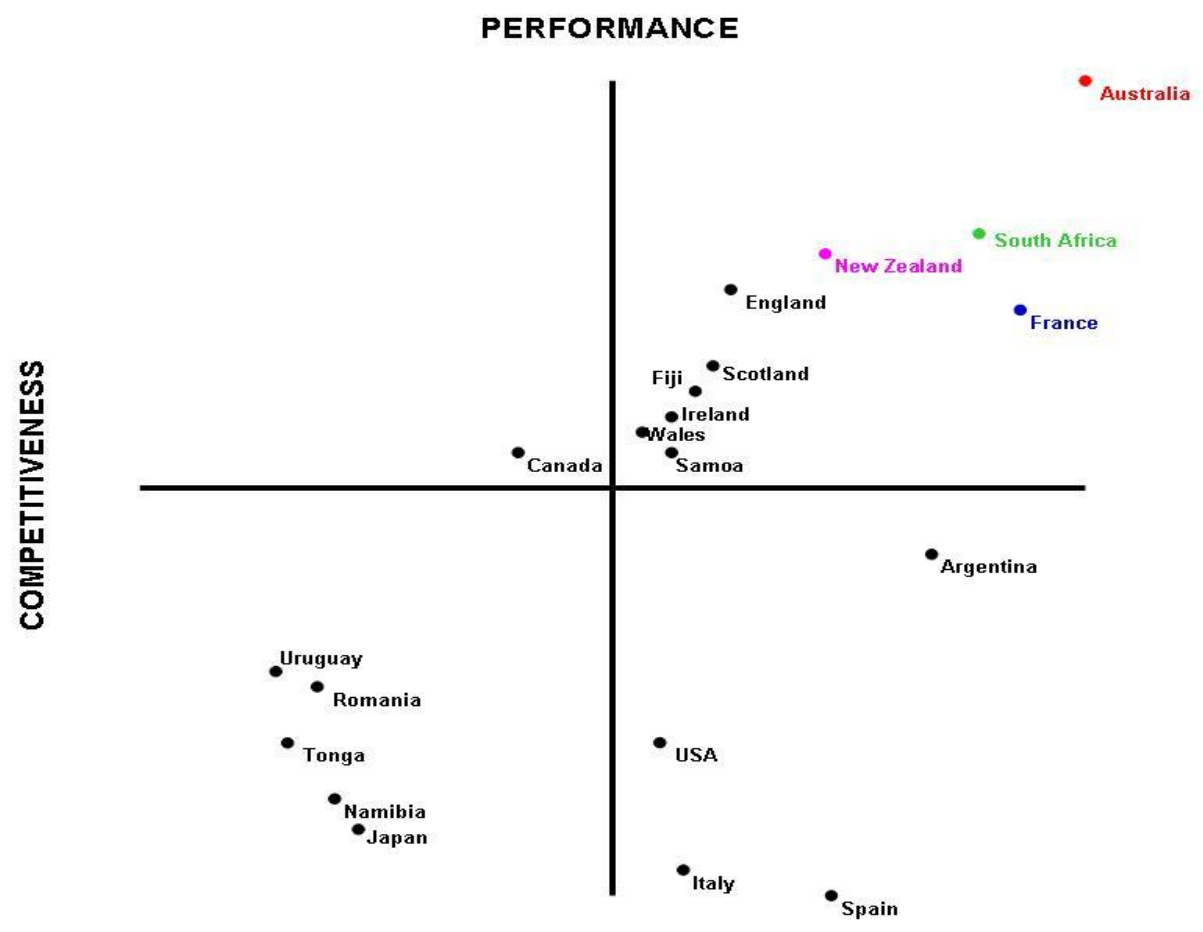

(Source: www.rugbyworldcup.com)

As a point of contrast with the 1987 and 1999 tournaments, all the other tournaments have seen winners who have competed in very different ways; None of the other tournaments have seen a single team dominate but rather they have seen a number of teams contesting at similar levels overall. In these tournaments the winner has had a slightly different blend of performance and competitiveness to the other teams. In 1991, for example, Australia won primarily on the basis of having higher performance than other teams but, in the 1995, 2003 and 2007 tournaments, the winning teams were those with the highest levels of competitiveness. In each of these cases, the performance levels of the winners, whilst being high, were not the highest in the tournament and these gaps in performance level were plugged by superiority in competitiveness. Figure 4 offers an illustration of this with the most recent RWC held in 2007. Despite being only the third best team by performance, South Africa were able to win on the basis of their competitiveness. 


\section{Figure 4: Performance-Competitiveness matrix for the 2007 RWC}

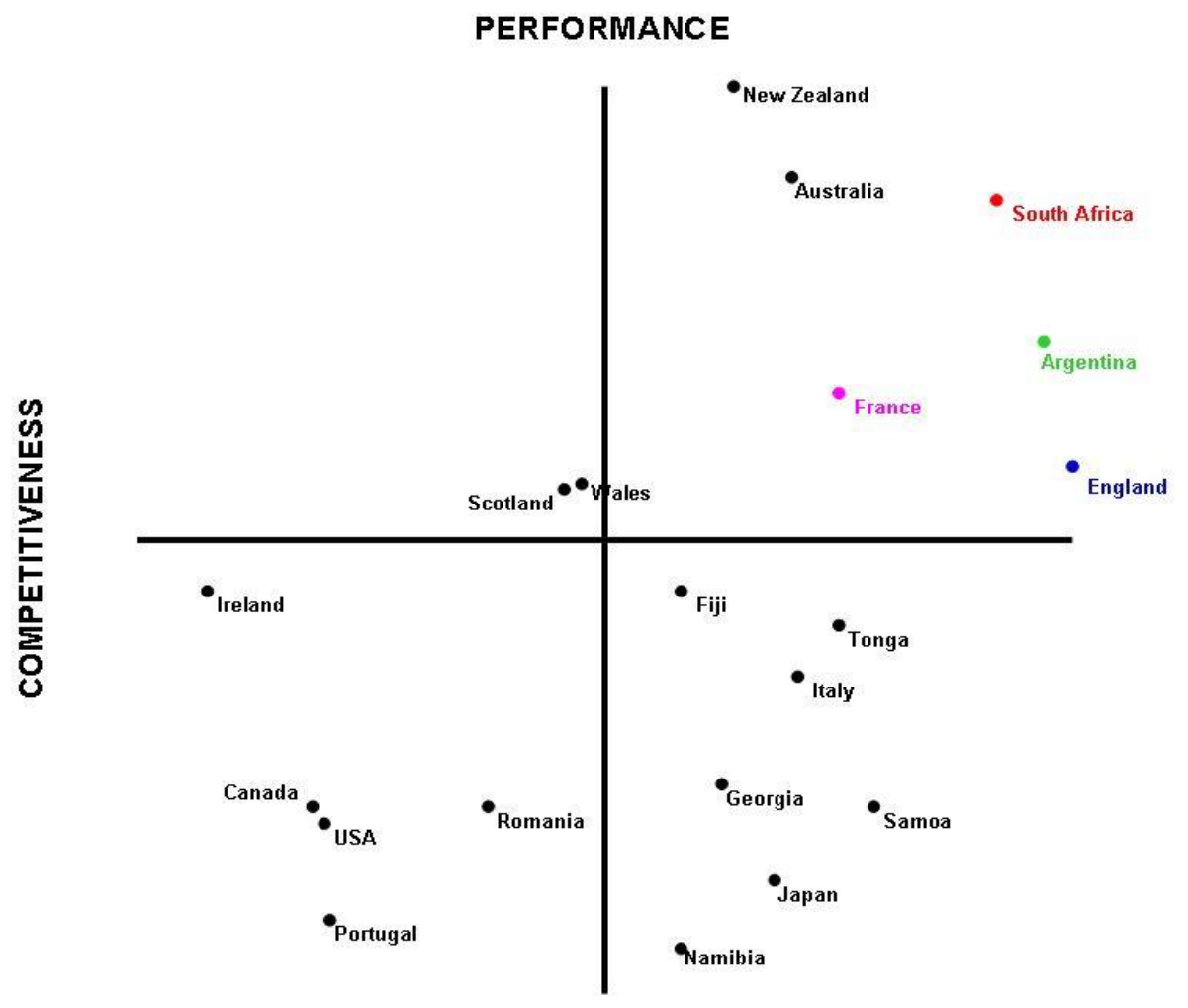

(Source: www.rugbyworldcup.com)

Overall, our first general conclusion about all this is that high levels of performance are a fundamental prerequisite for success in the RWC; absolutely all of the winners had high levels of performance and so a poor team has never won the RWC. However, under some circumstances, the highest levels of performance are not sufficient in themselves to deliver the ultimate outcome. Successful teams also need to demonstrate high levels of competitiveness. This is shown in the matrix for the 2007 RWC and, as another point of reference, we could also consider England's victory in the 2003 tournament. In 2003 there were three teams operating with high levels of performance; Australia, New Zealand and England had performance levels of between 100 and 96 and, under these conditions, competitiveness was the main determinant of who won overall. As Figure 5 shows, whilst there was little too choose between the three teams in terms of performance, there were significant gaps in competitiveness with England dominating by a significant margin. Thus when the performance of teams clusters around the same level, competitiveness will probably be decisive. 


\section{Figure 5: Performance-Competitiveness matrix for the $\mathbf{2 0 0 3}$ RWC}

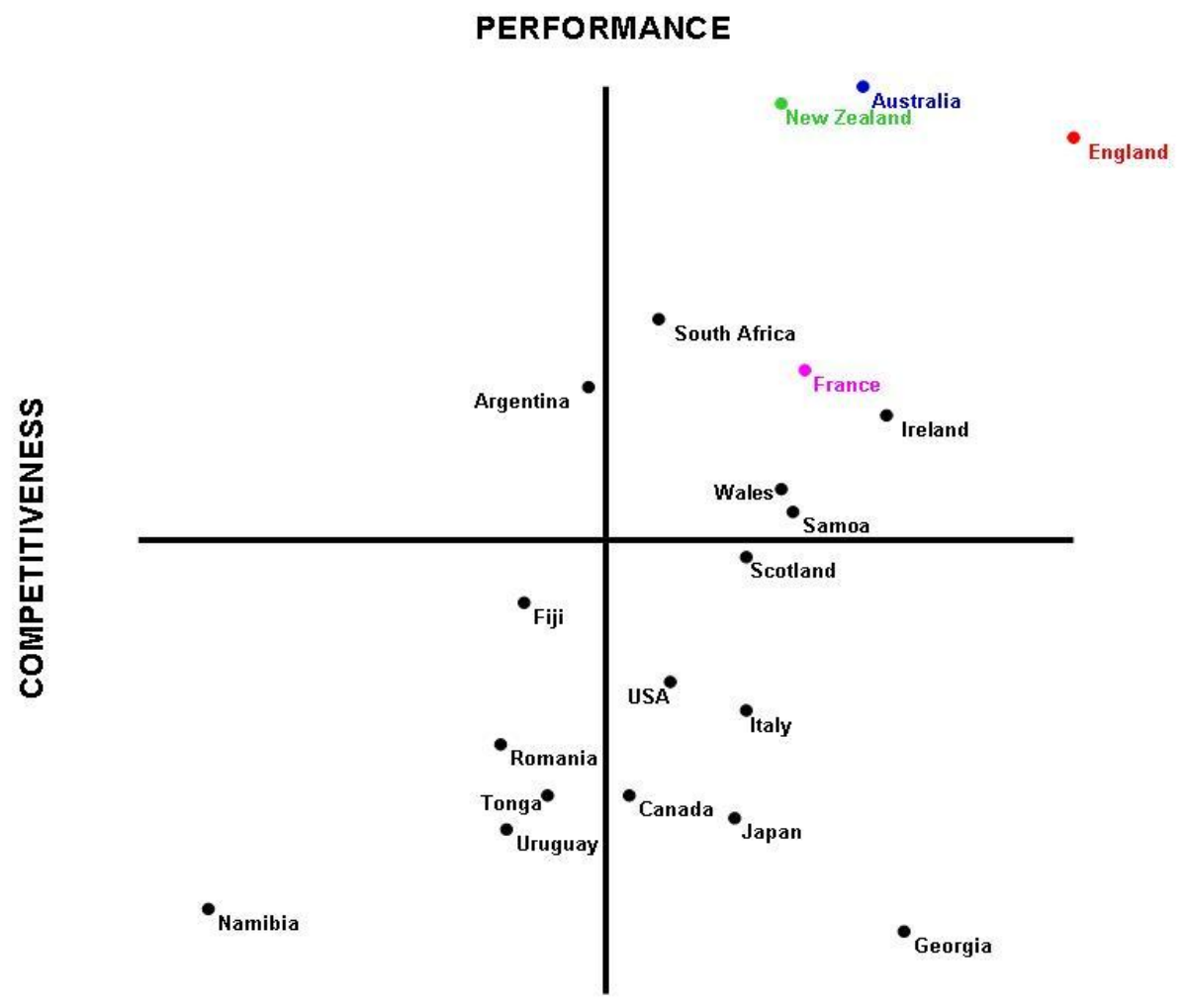

(Source: www.rugbyworldcup.com)

If, under some conditions, it is possible to overcome performance deficiencies, it is also important to consider when those conditions do not apply. Our analysis suggests that when the performance of one team is significantly superior, no amount of competitiveness will overcome it. For example in the 2003 RWC, whilst South Africa enjoyed a significant performance advantage over Georgia, the latter team enjoyed an advantage in competitiveness. However, this superiority was not a big enough advantage as South Africa won the game between the two teams by a margin of almost 30 points. In some games, perhaps, victory by one team is almost inevitable, especially when there is a large gap in performance. Rather obviously, this would also apply when one team enjoys an overwhelming superiority over all others in both orientations. Figure 6 shows the performance-competitiveness matrix for the first RWC in 1987 where New Zealand enjoyed such an overwhelming advantage that their victory was, to a large extent, inevitable. 


\section{Figure 6: Performance-Competitiveness matrix for the 1987 RWC}

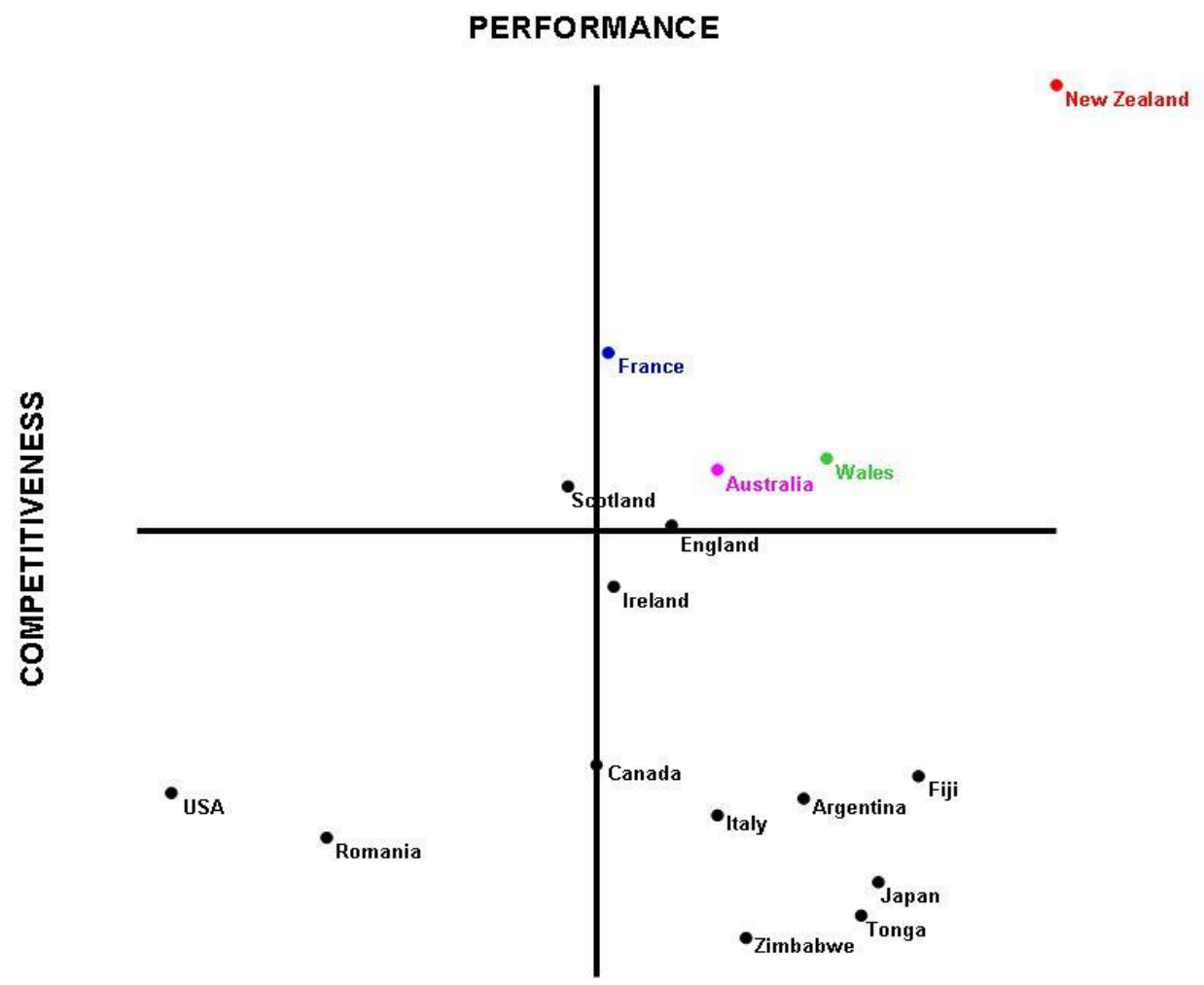

(Source: www.rugbyworldcup.com)

Whilst it is interesting to examine the nature and extent of competition in each individual tournament, it is also important to examine the patterns of competition that have developed across all six tournaments. Whilst for many the essence of sport is its unpredictability, our analysis suggests that the RWC is actually relatively stable and predictable over time. In examining teams who have competed in a minimum of four RWCs, over the course of all the tournaments, three distinct clusters of teams have developed. At the top of the performance and competitiveness scales are five teams who frequently appear in the semifinals, four of whom have won the tournament as a whole. In the middle is a second cluster made up of seven teams. These teams will frequently reach the quarter final stage of the tournament but usually go no further. Finally at the bottom is a cluster of teams who seem to be locked at this level and have hardly ever progressed from the group stages of any of the tournaments. Figure 7 shows these clusters. 


\section{Figure 7: Clusters of teams in the RWC}

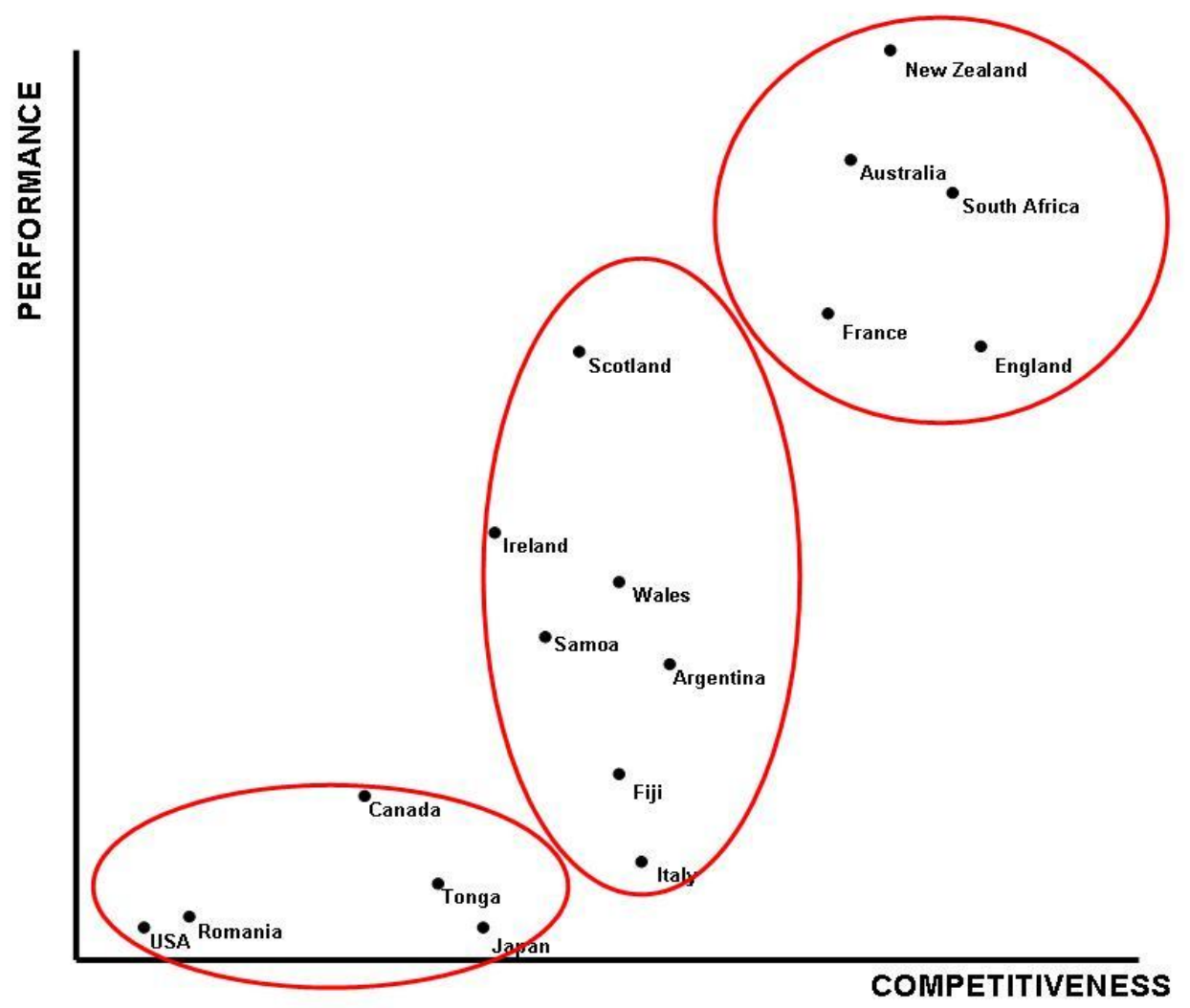

(Source: www.rugbyworldcup.com)

This clustering of teams gives further insights into the nature of competition in the RWC. Our argument would be that there are pockets of intense competition within clusters but a limited amount of competition between clusters. Over the six tournaments only a small number of teams have made the shift upwards between clusters. In 1991 Canada were able to make the quarter finals and Wales, Scotland and Argentina have made the semi-finals in 1987, 1991 and 2007 respectively. There has also been some movement downwards; all the teams in the top cluster have failed to reach the semi-finals at least once and similarly most of the teams in the middle cluster have failed to progress from the group stages at least once. What is striking, however, is the temporary nature of these movements; when teams have moved up or down in one tournament, they usually revert back to their normal cluster in the next one. This implies that this competitive structure is reasonably permanent and Table 6 illustrates this point by considering the average PC Score between each cluster. 
Table 6: Average PC Score difference between clusters

\begin{tabular}{|l|c|c|}
\hline & $\begin{array}{l}\text { Average PC Score } \\
\text { difference between top and } \\
\text { middle clusters }\end{array}$ & $\begin{array}{l}\text { Average PC Score difference } \\
\text { between } \\
\text { clusters }\end{array}$ \\
\hline $\mathbf{1 9 8 7}$ & 2357 & \\
\hline $\mathbf{1 9 9 1}$ & 3300 & 1617 \\
\hline $\mathbf{1 9 9 5}$ & 3833 & 2032 \\
\hline $\mathbf{1 9 9 9}$ & 3414 & 2143 \\
\hline $\mathbf{2 0 0 3}$ & 2884 & 1882 \\
\hline $\mathbf{2 0 0 7}$ & 3133 & 1706 \\
\hline
\end{tabular}

(Source: www.rugbyworldcup.com)

This lack of mobility is, therefore, an underlying trend in the RWC. For example, when the gap between top and middle was at its closest since 1987, in 2003, no team was able to break through into the highest cluster and, in 1995, when the gap between the middle and bottom clusters was at its lowest, again no team was able to break out into the higher cluster. Over time, the gap between the team at the top and the middle and between those in the middle and at the bottom has, if anything, widened. Given this stability, we now turn to examine the dynamics of competition within clusters and will use the top cluster containing the top 5 teams in the RWC as an example.

Figure 8 shows the quality of opposition faced by the winners of each RWC on the basis of their opponents PC Score. What the figure shows, amongst other things, is that there are two ways in which teams have built up competitiveness prior to playing in the final. In 1995 and 2003, competitiveness was developed in the tournament by a gradual ratcheting up of the quality of opposition where the tournament winners were not required to make a sudden or dramatic step up in the quality of opposition. In the other tournaments, competitiveness in the final was built by playing the strongest opposition earlier on the in tournament; in 1987, 1991, 1999 and 2007 the winning team had faced tougher opposition in the build up to the final than in the final itself. The final may well, therefore, have been the highest pressure match but it was not played against the strongest opposition. 
Figure 8: Quality of opposition faced by RWC winners by PC Score

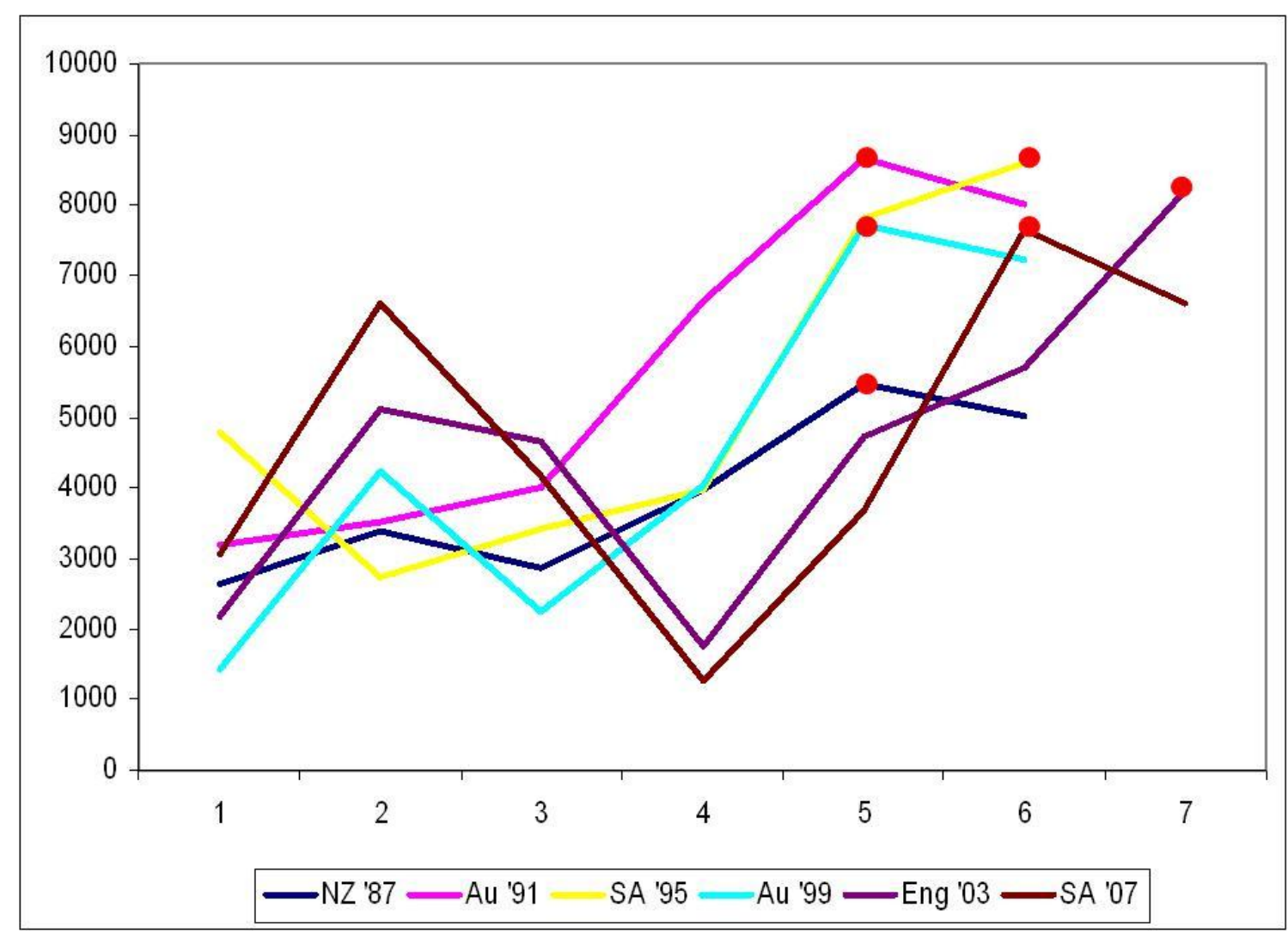

(Source: www.rugbyworldcup.com)

The patterns of quality of opposition faced by the winners is in stark contrast to that faced by the runners up in each tournament. Figure 9 shows the quality of opposition faced by the losing finalists in each tournament and, as in Figure 8, the game against the strongest opposition is highlighted. What this reinforces is the notion that it is the blend of both performance and competitiveness that matters in winning the tournament overall. In each RWC the runner-up has played their toughest game in the final, which they lost, and in most cases that final represented a significant step up in the quality of opposition. For example, in 1995 New Zealand went into the final having scored significantly more points and tries than anyone else. However, this performance advantage had been gained against relatively weak opposition whereas the winning finalists, South Africa, had more narrowly beaten significantly tougher opposition throughout the tournament. This development of competitiveness may well have proved the difference in a close final in which just three points separated winner and loser. 
Figure 9: Quality of opposition faced by RWC runners-up by PC Score

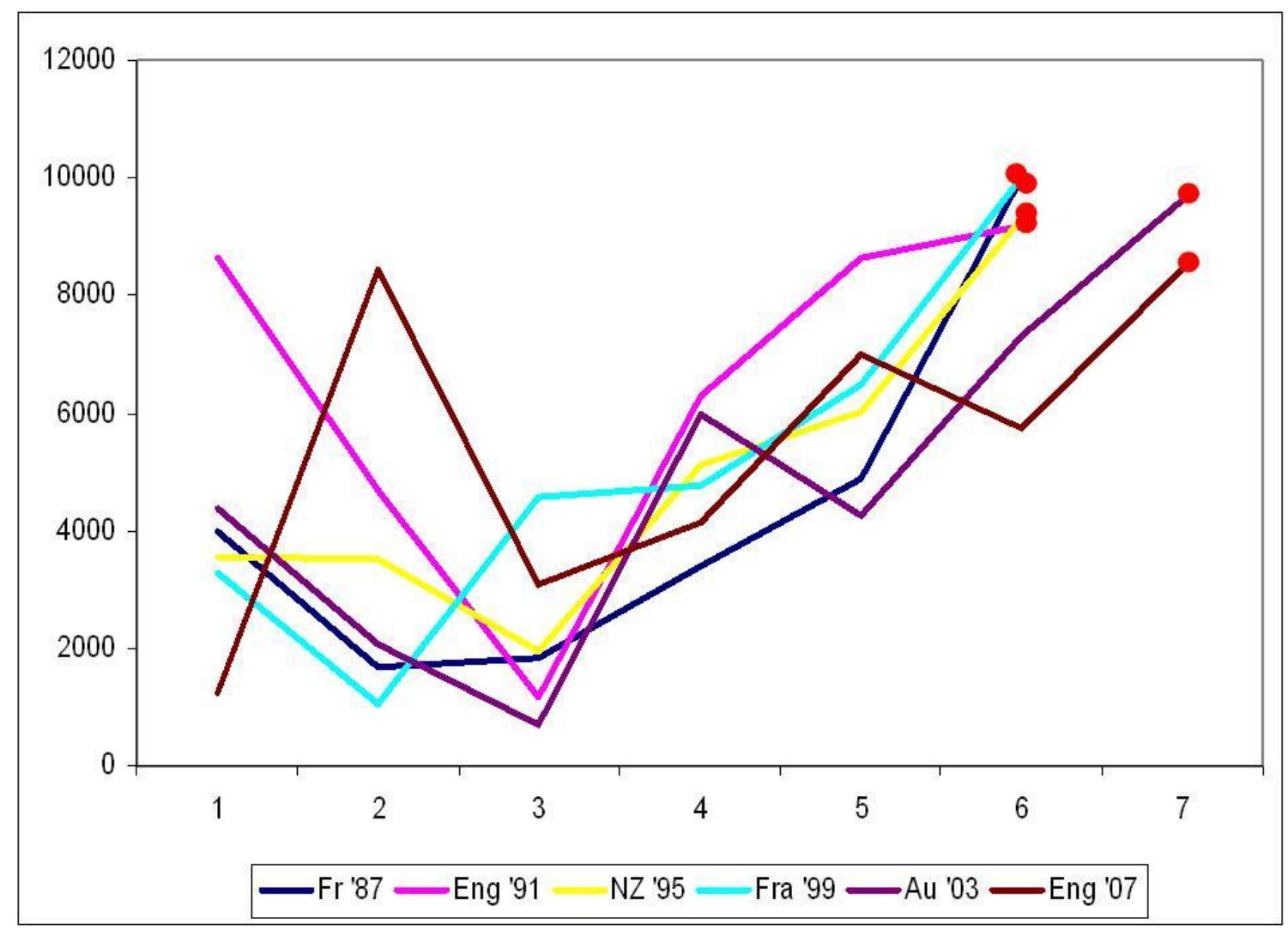

(Source: www.rugbyworldcup.com)

The example of New Zealand losing the 1995 final to South Africa is an important one as it illustrates the limits of performance superiority without competitiveness. As Figure E showed, New Zealand are the highest performing team across all six tournaments. During these tournaments they have scored more points and tries than any other team, they are the only team to have won all of their group games and in half of all the RWCs they have been the best performing team. However, they have rarely been able to translate this performance superiority into overall victory as they have won the RWC just once. Our explanation of this would be that they have lacked the necessary competitiveness. For example, across all the games they have played in the RWC, New Zealand have failed to win the try count in just five of them. All of these games have been lost and New Zealand have been eliminated from the tournament. As Figure 10 shows, in four out of these five games, New Zealand have had to make a distinct step up in the quality of opposition faced and have failed to do that. In this case, competitiveness is not built through heavy point and try scoring against the weakest opposition. 
Figure 10: Quality of opposition faced by New Zealand by PC Score

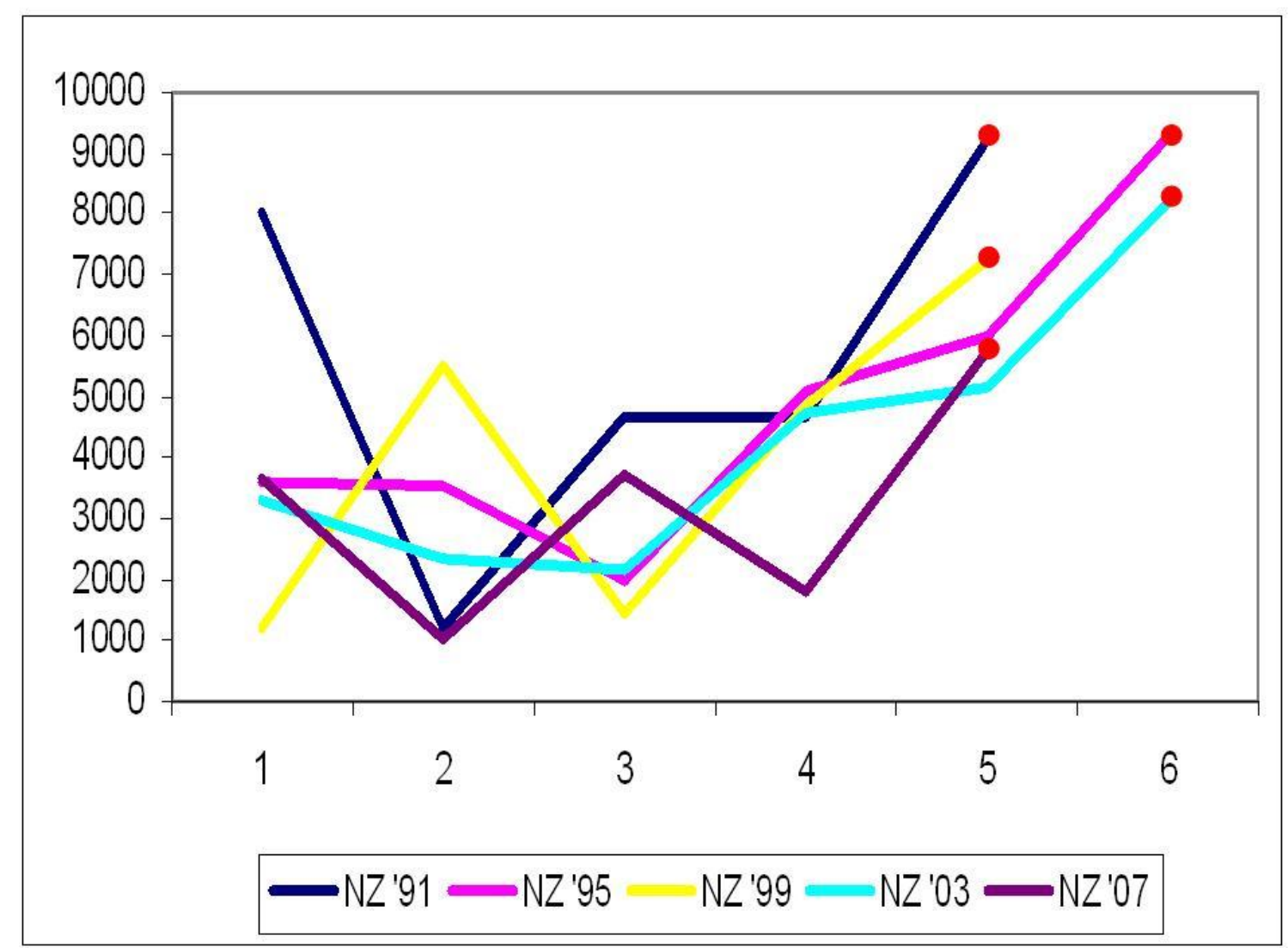

(Source: www.rugbyworldcup.com)

If the New Zealand example shows the limitations of performance without competitiveness then an examination of England in the RWC shows the limits of competitiveness without performance. Over the course of the six tournaments, England have consistently been the most competitive team. As we have seen already, their victory in the 2003 tournament was achieved on the basis of their superior competitiveness and they have also reached two other finals in 1991 and 2007. Figure 11 below shows the performance-competitiveness matrix for the 1991 RWC. 


\section{Figure 11: Performance-Competitiveness matrix for the 1991 RWC}

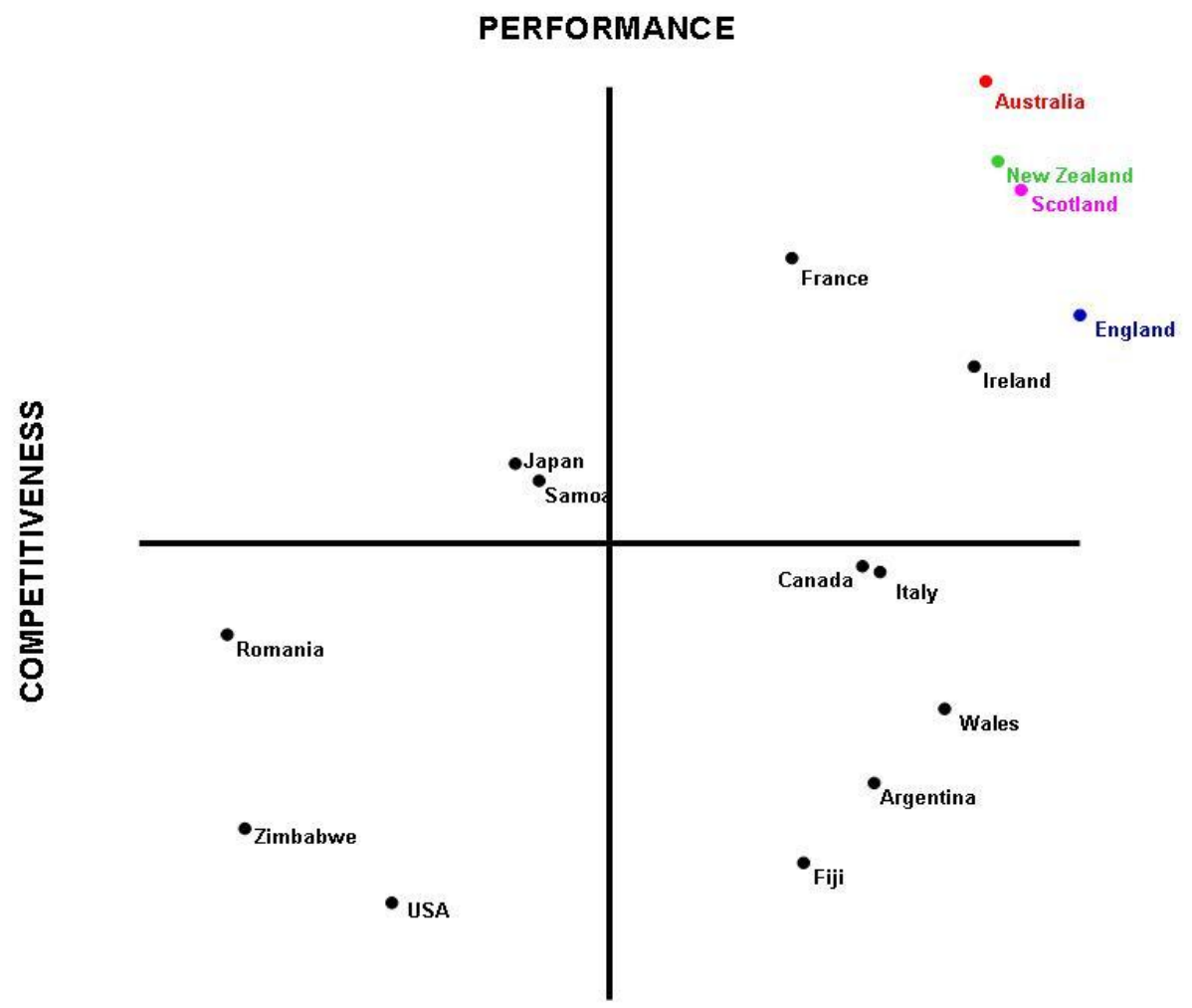

(Source: www.rugbyworldcup.com)

In 1991 England were able to reach the final despite playing France and Scotland in the quarter and semi-finals respectively, two teams which enjoyed a significant advantage in performance. This performance deficit was overcome by England's superior competitiveness. There was a similar pattern in 2007 (see Figure B) where England beat the superior performing Australia and France. Table 7 illustrates the gaps in performance and competitiveness that England encountered in the 1991 and 2007 tournaments. 
Table 7:

England

\section{Performance and competitiveness gaps encountered by}

\begin{tabular}{|l|c|c|c|}
\hline & Performance Gap (\%) & $\begin{array}{l}\text { Competitiveness Gap } \\
(\%)\end{array}$ & Result \\
\hline 1991 RWC & \multicolumn{3}{|l|}{} \\
\hline France & -3.6 & +31.6 & Victory \\
\hline Scotland & -13.0 & +6.4 & Victory \\
\hline Australia & -20.0 & +8.7 & Defeat \\
\hline 2007 RWC & \multicolumn{3}{|l}{} \\
\hline Australia & -27.5 & +29.9 & Victory \\
\hline France & -8.3 & +25.0 & Victory \\
\hline South Africa & -26.7 & +6.4 & Defeat \\
\hline
\end{tabular}

(Source: www.rugbyworldcup.com)

As the table shows, competitive superiority was only able to take England so far in each of two tournaments. In 1991, relatively small performance differences were overcome by competitive superiority but the gap between England and the winner of the 1991 RWC, Australia, was simply too wide to bridge. The 2007 example illustrates the complexity of the relationship and blend between performance and competitiveness. For example, England were able to beat Australia despite a larger performance differential than against South Africa to whom they lost in the final. The explanation for this lies in the competitiveness advantage which England enjoyed against these two opponents; it was large enough to compensate against Australia but not against South Africa.

Our main conclusion from this analysis is that explaining success in this tournament requires a multi-dimensional approach which takes account of both performance and competitiveness and, crucially, the relationship between the two. Whilst the tournament has, to an extent, stabilised into distinct clusters of teams with little movement or dynamic between them, within each cluster competition is dynamic and subject to change. Where there is change, from tournament to tournament, it is through teams changing their blends. Historically, whilst teams have done well through being strong in either performing or competing, teams have only ever won the tournament when they have the right blend of these characteristics.

\section{Conclusions}

The main aim of this paper was to explore the versatility of management theories and concepts by using them to explore a non-management phenomena. Having analysed the six RWCs that have taken place since 1987, this final section will consider three issues. First, we will briefly discuss the lessons for sport generally and rugby union specifically from this analysis. Second, we will 
consider the extent to which lessons can be learnt for both the theory and practice of management and, finally, we will consider the future directions that research in this area could take.

Damon Runyon suggested that whilst the race may not always be to the swift and the battle to the strong, that was usually "the way to bet". In this context, the academic answer to the simple question of whether the best team always wins the Rugby World Cup is always likely to be "depends". It depends on how the best team is defined and measured and it also depends on how the best team plays. One of the contradictions of sport is that outcomes are always relatively easy to measure but processes are much more open to debate. Outcomes will tend to come in the form of win, lose or draw but the multitude of internal and external factors which make up the process of playing and competing frequently defies simple explanations. In trying to understand this complexity of process, our first suggestion is that high performance is frequently not enough. It matters massively because it is the basic entry level criteria for success of any sort but, in a sporting environment where the contestants are often more similar than they are different, it is only one part of the equation. The other part is competitiveness which is more opaque, difficult to define and harder to measure. Just as great sporting teams are defined by their combinations, arte et labore, so to are sporting outcomes explained by their combinations of performing and competing. In an ideal situation, teams will have both but, as the New Zealand teams post 1987 have shown, this combination is usually the exception rather than the rule.

We are wary of drawing any general conclusions about management from the theory and evidence contained in this paper. Most management research is context specific and this paper is no different as it deals with a very specific and non-traditional example. Instead of general lessons, therefore, we would much rather consider how this example reinforces existing theories of management. In his poem "Heavy Date" W.H. Auden talked about how life is a collection of "emphatic dogmas". The general study of management suggests that it is all about the generation, allocation and organisation of available resources and, in the management field of strategy, the emphatic dogma is that of the relationship between the organisation and its environment. There is much in our analysis that reinforces these dogmas and so, disappointingly perhaps, the best we have to offer to the study of management is further proof of something we already know to be true. Whilst there may be little that is new or novel for management, we have at least demonstrated its versatility in examining an essentially nonmanagement phenomena in a way that generate robust conclusions that are both valid and reliable.

Usually the most interesting element of management research is not the arguments that are closed or debates that are settled but rather the avenues of 
investigation which are opened up. This paper opens up two avenues, one theoretical and conceptual in nature and the other more contextual. Theoretically and conceptually there is still much work to be done in further developing ideas about performance and competitive orientation. The theoretical intervention offered in this paper is primarily post-rational in nature and is based around assessment of these orientations after they have taken place. Perhaps, therefore, there is scope for further investigation which aims to predict such behaviour. Contextually, the robustness of the conclusions can be investigated further with expansion of the analysis into other sports, the options for which are many in terms of sports with a heavy numbers orientation such as cricket, baseball, tennis and golf. The success of this paper should not be judged on its own impact factor but rather the extent to which like minded (or otherwise) social scientist extend the theoretical and contextual discussions.

\section{References}

Adcroft, A. and Willis, R. (2005) The (un)intended outcome of public sector performance measurement in International Journal of Public Sector Management, Volume 18, number 5.

Ashton, D. and Sung. J. (2002) Supporting Workplace Learning for High Performance Working, International Labour Office, Geneva.

Applebaum, E., Bailey, T., Berg, P. and Kellberg, A. (2000) Manufacturing Advantage, Cornell University Press, USA.

Boland, T. and Fowler, A. (2000) A systems perspective of performance management in public sector organisations in International Journal of Public Sector Management, volume 13, number 5.

Butler, P., Felstead, A., Ashton, D., Fuller, A., Lee, T., Unwin, L. and Walters, S. (June 2004) High Performance Management: A literature review, Learning as Work Research Papers, number 1, University of Leicester.

Chaharbaghi, K. and Willis, R. (1996) Strategy: The missing link between continuous revolution and constant evolution in International Journal of Operations and Production Management, volume 18, number 9/10.

Coad, A. F. and Berry, A. J. (1998) Transformational leadership and learning orientation in Leadership and Organisational Development Journal, volume 19, number 3 .

Coad, A. F. (1999) Some survey evidence on the learning and performance orientations of management accountants in Management Accounting Research, volume 10.

Covin, J. G. and Covin, T. J. (1990) Competitive Aggressiveness, Environmental Context and Small Firm Performance in Entrepreneurship Theory and Practice, Summer.

Espitia-Escuer, M. and Garcia-Cebrian, L. I. (2006) Performance in Sports Teams: Results and potential in the professional soccer league in Spain in Management Decision, volume 44, number 8. 
Gatignon, H. and Xuereb, J-M. (February 1997) Strategic Orientation of the Firm and New Product Performance in Journal of Marketing Research, volume 34.

Huber, G., Ullman, J. and Leifer, R. (1979) Optimum Organization Design: An analytic-adoptive approach in Academy of Management Review, volume 4, number 4.

Huddleston, S. and Garvin, G. W. (September 1995) Self-evaluation compared to coaches evaluation of athletes competitive orientation in Journal of Sports Behaviour, volume 18, issue 3.

Kaplan, R. S. and Norton, D. P. (1992) The Balanced Scorecard measures that drive performance in Harvard Business Review, JanuaryFebruary.

Keep, E. (2000) Creating a Knowledge Driven Economy - Definitions, Challenges and Opportunities, SKOPE Policy Paper number 2, University of Warwick.

Liu, J., Srivastava, A. and Woo, H. S. (1998) Transference of skills between sports and business in Journal of European Industrial Training, volume 22, number 3.

Lloyd, C. and Payne, J. (2004) The only show in town (if a pretty pathetic one at that)...Re-evaluating the high performance workplace as a vehicle for the UK high skills project from the proceedings of the International Labour Process Conference, Amsterdam.

Lyle, J. W. B. (1997) Managing excellence in sports performance in Career Development International, volume 2, number 7.

Modell, S. (February 2004) Performance Measurement Myths in the Public Sector: A research note in Financial Accountability and Management, volume 20, number 1 .

Ness, J. and Cucuzza, T. (1995) Tapping the full potential of $A B C$ in Harvard Business Review, July-August.

Perry, M. L. and Shao, A. T. (2005) Incumbents in a dynamic internet related services market: Does customer and competitive orientation hinder or help performance? In Industrial Marketing Management, volume 34.

Porter, C. O. L. H. (2005) Goal Orientation: Effects on backing up behaviour, performance, efficacy and commitment in teams in Journal of Applied Psychology, volume 90, number 4.

Radnor, Z. and McGuire, M. (2004) Performance management in the public sector: Fact or fiction? in International Journal of Productivity and Performance Management, volume 53, number 3.

Ryckman, R. M., Libby, C. R., van den Borne, B., Gold, J. A. and Linder, M. A. (1997) Values of hypercompetitive and personal development competitive individuals in Journal of Personality Assessment, volume 69, number 2. 
Simons, J., Dewitte, S. and Lens, W. (2000) Wanting to have vs. wanting to be: The effect of perceived instrumentality on goal orientation in British Journal of Psychology, volume 91.

Stiles, P., Gratton, L., Truss, C., Hope-Hailey, V. and McGovern, P. (1997) Performance management and the psychological contract in Human Resource Management Journal, volume 7, number 1.

Williams, K., Haslam, C., Williams, J., Johal, S. and Adcroft, A. (1993) Deconstructing car assembler productivity in International Journal of Production Economics, volume 34, issue 3. www.rugbyworldcup.com 